\title{
On energy-dependent cues in duration discrimination*
}

\author{
R. M. CARBOTTE and A. B. KRISTOFFERSON \\ McMaster University, Hamilton, Ontario, Canada
}

\begin{abstract}
We consider the possibility that, in a duration discrimination task involving very short empty time intervals, $T$ and $T+\Delta T$, bounded by brief auditory pulses, there may be a critical value of the base duration $T$ within the range $50-300 \mathrm{msec}$ below which duration is coded on the basis of sensory interactions between the markers which bound the interval. With $\Delta \mathrm{T}$ fixed at $10 \mathrm{msec}$, the functional relation between performance and base duration was determined under three levels of marker intensity. Changing the intensity by $37 \mathrm{~dB}$ resulted in the same small change in performance at the shortest base duration $(50 \mathrm{msec})$, where it is most likely that an intensity-dependent interaction could be present, as was obtained at the longest base duration $(250 \mathrm{msec})$, where such an interaction should be minimally effective as a cue for duration discrimination. The code for the duration of an empty auditory interval greater than 50 msec probably is not derived from energy-dependent processes.
\end{abstract}

When an $\mathrm{O}$ discriminates between two very brief intervals, $T$ and $T+\Delta T$, what is the nature of the code on which the discrimination is based when $T$ is in the range of 50 to $300 \mathrm{msec}$ ? Several quantitative models have been proposed, which assume that a central timing mechanism is involved in duration discrimination, a central mechanism that does not use information from the sensory events defining an interval other than that defining the boundaries of the "internal interval" that is to be measured (Creelman, 1962; Allan, Kristofferson, \& Weins, 1971; Carbotte \& Kristofferson, 1971). On the other hand, the discrimination might be based on a sensory code. There is no a priori reason to expect that, with a $250-\mathrm{msec}$ separation between two brief auditory pulses, there is no longer any interaction between the sensory effects of these pulses. Plomp (1964) infers a 200-300-msec delay for the sensation due to an auditory pulse to decay to its threshold value, and Massaro (1969) has found that a masking tone interferes with the identification of the pitch of a brief preceding test tone until the interval between the test and masking tones is of the order of $250 \mathrm{msec}$. Hence, the code for a time interval bounded by two brief auditory pulses could conceivably be based on a sensory interaction (facilitation or inhibition) between the pulses, this interaction being a function of their temporal separation. Another possibility is that the time information is inferred from the decay of the excitation due to the first pulse, with the second serving anly as a signal to take a measure of the excitation remaining in some display area. Finally, the time-intensity reciprocity obtained in many tasks involving stimulus durations less than certain critical values raises the question as to whether the coding of a very brief time interval might not be based on the information along psychological dimensions other than duration-apparent brightness or loudness, for example (Stevens \& Hall, 1966).

*This research was supported by Grant A-7919 from the National Research Council of Canada to A. B. Kristofferson. This report is condensed from a doctoral dissertation submitted to McMaster University in October 1972 by R. M. Carbotte.
Evidence is accumulating which supports the conclusion that amplitude and total energy of the stimuli defining brief time intervals are not important parameters in duration discrimination, even for very short intervals of the order of $100 \mathrm{msec}$ or less. This conclusion is suggested for both filled and empty intervals, and in both the visual and auditory modalities. With intervals in the range of 0 to $75 \mathrm{msec}$, Nilsson (1969) found that the difference thresholds for empty intervals bounded by $1-\mathrm{msec}$ light flashes were not significantly affected by changes in the luminance level of the flashes: these levels were 50, 200, and 2,000 ml. An analysis of variance indicated no statistically significant interaction between luminance and base duration. Allan et al (1971) found that changing the luminance difference between two very brief light flashes (100 and $120 \mathrm{msec}$ ) did not affect performance when Os were asked to discriminate on the basis of duration and were not informed about the luminance difference. These luminance differences were large enough to have been used as a cue for the discrimination, since performance did vary with the size of the luminance difference when Os were asked to discriminate on the basis of luminance, and the duration difference was reduced to zero.

When durations are defined by auditory stimuli, most of the available evidence supports a similar conclusion regarding the relative unimportance of energy and intensity in duration discrimination with very short intervals. Creelman (1962) examined the effect of increasing signal voltage on the discrimination of a pair of filled auditory intervals of 100 and $130 \mathrm{msec}$ duration. Performance improved rapidly with increasing signal voltage at low signal-to-noise ratios, but then appeared to level off and become independent of signal intensity. The interpretation of these results was that the effect of increasing the intensity was to reduce the uncertainty in the onset and offset of the intervals to be measured: at low intensities, there may be difficulty in detecting the presence of the signal against the noise background. However, in another experiment, there appeared to be an interaction between base duration and 
intensity in their effects on duration discrimination. He examined the change in the discriminability of a duration difference $\Delta T$, when $\Delta T$ was fixed at $40 \mathrm{msec}$ and the base duration was increased from 40 to $640 \mathrm{msec}$. Two intensity levels were used, one above and one below the level at which asymptotic performance seemed to occur in his first experiment. The difference in intensity levels resulted in a larger difference in the performance measure $\mathrm{d}^{\prime}$ with a small base duration (80) than it did at a larger one $(320 \mathrm{msec})$, and this difference appeared to decrease monotonically as the base duration increased. On the other hand, if we translate these $d^{\prime}$ values from a 2AFC task back into $\hat{\mathbf{P}}(\mathrm{C})$ values [by using Table II in the appendix of Swets (1964) and assuming no response bias], we find that the intensity difference resulted in about the same difference in $\hat{P}(C)$ at $T=320$ as it did at $T=80$, and is of the order of .15 . This is true as well for the $d^{\prime}$ values from a replication of the experiment, using a different group of Os and a slightly different set of base durations. Hence, if $\dot{\mathbf{P}}(\mathrm{C})$ were used as the dependent variable, one might conclude that there was no interaction between the effects of intensity and base duration on duration discrimination of filled intervals.

In the discrimination of even shorter empty intervals bounded by brief auditory pulses $(2,000-\mathrm{Hz}$ tones $)$, Abel (1970) found that changing the duration of the pulses, and hence their total energy, had no effect on performance. Os' ability to discriminate between intervals of 25 and $30 \mathrm{msec}$ did not change systematically as the duration of the first (second) pulse bounding the interval was varied from 4 to $16 \mathrm{msec}$, while the second (first) was kept fixed at $10 \mathrm{msec}$.

In a later study, Abel (1972b) varied both the duration and the intensity of noise burst markers bounding empty intervals ranging in base duration, $T$, from .64 to $640 \mathrm{msec}$. Three conditions were run successively, allowing for comparison of performance at two intensity levels and with two values for the total energy in the markers. In these conditions, the parameters of the markers were (a) $10 \mathrm{msec}, 85 \mathrm{~dB}$; (b) $300 \mathrm{msec}, 70 \mathrm{~dB}$; (c) $10 \mathrm{msec}, 70 \mathrm{~dB}$. Over the entire range of $T$, she found that the difference thresholds, $\Delta T_{.75}$, were consistently less with the $85-\mathrm{dB}$ markers than with the 70-dB markers, whereas the functions relating $\Delta \mathrm{T}_{.75}$ to base duration from Conditions $\mathrm{b}$ and $\mathrm{c}$ overlapped each other when plotted on log-log scales. For intervals of less than $160 \mathrm{msec}$, the intensity of the markers seemed to be an important parameter for the discrimination. The changes in the Weber ratio, $\Delta \mathrm{T}_{.75} / \mathrm{T}$ at base durations of 40,80 , and 160 were $.15, .125$, and .03 , respectively, suggesting that intensity becomes less important as the base duration increases. But on the other hand, the change in the average $\Delta \mathrm{T} .75$ resulting from a decrease in intensity from 85 to $70 \mathrm{~dB}$ was $6 \mathrm{msec}$ when $T=40$ and $5 \mathrm{msec}$ when $T=160$, while it was $10 \mathrm{msec}$ when $T=80$. This result suggests that the change in $\Delta T_{.75}$ due to a change in intensity might not be a monotonic function of base duration over the range of $40-160 \mathrm{msec}$. It is difficult to interpret these results, especially since her procedure yielded values for the Weber ratios that were two to three times larger than those obtained for empty auditory intervals by previous investigators (Woodrow, 1953). Abel (1972a) used a different procedure in investigating duration discrimination of filled auditory intervals in the range of $.16-960 \mathrm{msec}$, and found that the discrimination was independent of the physical parameters of the stimuli, including intensity.

The following experiment was an attempt to determine whether there was a critical value for the base duration, $\mathrm{T}$, within the range of $50-300 \mathrm{msec}$, below which varying the intensity of the auditory stimuli bounding an empty interval influences an important cue for discriminating between the two patterns defining the intervals $T$ and $T+\Delta T$. If there is a critical duration within this range, then when performance is plotted as a function of base duration with intensity as a parameter, the separation between these curves at various intensities should decrease as $T$ increases, up to the critical value of $T$, beyond which the separation is independent of base duration; the effect on performance resulting from a change in marker intensity from high to moderate, or from high to low, should diminish as the base duration is increased.

\section{APPARATUS AND PROCEDURE}

All events on each trial were controlled by a PDP-8/S computer interfaced to an electronic switch (Grason-Stadler), which gated a $2,000-\mathrm{Hz}$ sine wave at zero crossings in its cycle. The rise-decay times of these pulses were set at $1 \mathrm{msec}$, and their duration was programmed for $10 \mathrm{msec}$. The intensities of the four pulses defining the two time intervals presented on each forced-choice trial were identical. The auditory signals were presented to the $O$ binaurally over earphones; the $O$ was seated in a sound-attenuated cubicle isolated from the experimental control room.

On each trial, a 250-msec visual warning signal was followed $2 \mathrm{sec}$ later by a pattern of four brief auditory pulses. The intervals to be discriminated were those between the offset of the first and the onset of the second pulse $\left(T_{1}\right)$ and between the offset of the third and the onset of the fourth pulse $\left(T_{2}\right)$. The interval between Pulses 2 and 3 was designated as the interstimulus interval (ISI); it was fixed at $1.5 \mathrm{sec}$. The $O$ was instructed to indicate whether $T_{1}$ or $T_{2}$ was the longer interval by pressing one of two microswitches interfaced with the computer. He was told that the longer interval was as likely to be first as second. If a correct response was made within $4 \mathrm{sec}$ of the end of $T_{2}$, feedback was given in the form of two $125-\mathrm{msec}$ light flashes. The next trial began $1.5 \mathrm{sec}$ later.

\section{Experiment 1}

Each 1-h session consisted of three blocks of 90 trials. Within each block, the intensity of the signals bounding the intervals was kept constant, but this intensity was changed from block to block. The intensity readings, as measured at the switch, were $.08, .3$, and $6 \mathrm{rms} \mathrm{V}$, and the corresponding sound pressure level of continuous tones, as measured at the earphones, were 61,72 , and $98 \mathrm{~dB}$ (re .0002 microbar). With no signal being presented, the sound-level reading under the earphones was $54 \mathrm{~dB}$, because 
Table 1

The Proportion of Correct Responses $\dot{P}(C)$ at Each Base Duration for Each Intensity Condition (Individual Data)

\begin{tabular}{|c|c|c|c|c|c|c|c|}
\hline $\mathrm{O}$ & $\mathrm{T}$ & \multicolumn{3}{|c|}{ Experiment 1} & \multicolumn{2}{|c|}{ Experiment II } & \\
\hline J.T. & $\begin{array}{r}50 \\
150 \\
250\end{array}$ & $\begin{array}{l}.951 \\
.781 \\
.729\end{array}$ & $\begin{array}{l}.922 \\
.759 \\
.688\end{array}$ & $\begin{array}{l}.911 \\
.709 \\
.710\end{array}$ & $\begin{array}{l}.885 \\
.726 \\
.683\end{array}$ & $\begin{array}{l}.872 \\
.669 \\
.659\end{array}$ & $(\mathrm{~N}=440)$ \\
\hline R.M. & $\begin{array}{r}50 \\
150 \\
250\end{array}$ & $\begin{array}{l}.962 \\
.904 \\
.845\end{array}$ & $\begin{array}{l}1.00 \\
.862 \\
.812\end{array}$ & $\begin{array}{l}.982 \\
.845^{*} \\
.843\end{array}$ & $\begin{array}{l}.981 \\
.909 \\
.889\end{array}$ & $\begin{array}{l}.950^{*} \\
.826^{*} \\
.848\end{array}$ & $(\mathrm{~N}=420)$ \\
\hline V. & $\begin{array}{r}50 \\
150 \\
250\end{array}$ & $\begin{array}{l}.690 \\
.731 \\
.750\end{array}$ & $\begin{array}{l}.650 \\
.786 \\
.674\end{array}$ & $\begin{array}{l}.650 \\
.721 \\
.670^{*}\end{array}$ & $\begin{array}{l}.706 \\
.700 \\
.609\end{array}$ & $\begin{array}{l}.704 \\
.614^{*} \\
.595\end{array}$ & $(\mathrm{~N}=300)$ \\
\hline
\end{tabular}

Note-A sterisks indicate where $\hat{P}(C \mid$ low $)$ is significantly less than $\hat{P}(C$ thigh $)$. For Experiment $I$, each $\hat{P}(C)$ is based on approximately 270 trials; in Experiment II, the number of observations $(N)$ for each $\hat{P}(C)$ is given in the last column.

of ambient noise from a fan ventilating the booth.

On any trial, either $S_{1}=[T+\Delta T, T]$ or $S_{2}=[T, T+\Delta T]$ could occur. The shorter interval in each of these pairs is referred to as the base duration. Three values of base duration $(50,150$, and $250 \mathrm{msec})$ and one value of $\Delta T(10 \mathrm{msec})$ were used. One value of $T$ was used over three consecutive sessions, then a second, and finally the third. The order of presentation of $T$ and the three intensity levels were counterbalanced among three Os. The order of presentation of $T$ for each $O$ was: V., 50, 150, 250; R.M., 150, 250. 50; and J.T.. 250. 50, 150.

The Os were student volunteers, paid $\$ 2$ per session. Two of the Os had participated in at least 32 sessions in a previous experiment, but the third (J.T.) was naive. All three were given two practice sessions. in which it was established that when the signal intensity was $.3 \mathrm{rms} V$ and $\Delta T=10$. the proportion of correct responses in discriminating between $T$ and $T+\Delta T$ would be at least .70 at each of the three base durations.

\section{Experiment 2}

The second experiment was essentially a replication of the first, but with all three values of $T$ intermixed randomly within all blocks. Hence, from trial to trial, the Os were uncertain as to the order of magnitude of the intervals that would occur. Only the high- and low-intensity levels were used; these alternated from block to block for 6 sessions for $V$. and for 10 sessions for J.T. and R.M.

\section{RESULTS}

Let $\mathrm{P}\left(1 \mid \mathrm{S}_{1}\right)$ denote the proportion of trials on which the $S_{1}$ pattern $[T+\Delta T, T]$ is presented and the first interval is correctly chosen as longer. It is an estimate of the probability of a correct response when the longer interval occurs first. $\hat{P}\left(2 \mid S_{2}\right)$ is defined in a similar way. When $S_{1}$ and $S_{2}$ occur equally often, one measure of the $O$ 's ability to discriminate between $T$ and $T+\Delta T$ is given by

$$
\hat{\mathrm{P}}(C)=1 / 2\left[\hat{\mathrm{P}}\left(1 \mid \mathrm{S}_{1}\right)+\hat{\mathrm{P}}\left(2 \mid \mathrm{S}_{2}\right)\right] \text {. }
$$

Table 1 shows this proportion of correct responses at each base duration for each intensity condition in Experiments 1 and 2.

We are interested in whether performance with the short base duration is more sensitive to a change in intensity than performance with much larger base durations. Figure 1 shows $\hat{\mathbf{P}}(\mathrm{C})$ as a function of base duration, with intensity as a parameter; the data are averaged over the three Os. ${ }^{1}$ In both versions, at each
Fig. 1. $\hat{\mathbf{P}}(\mathrm{C})_{\mathrm{av}}$ as a function of base duration, averaged over three Os. Boundary intensity is the parameter.
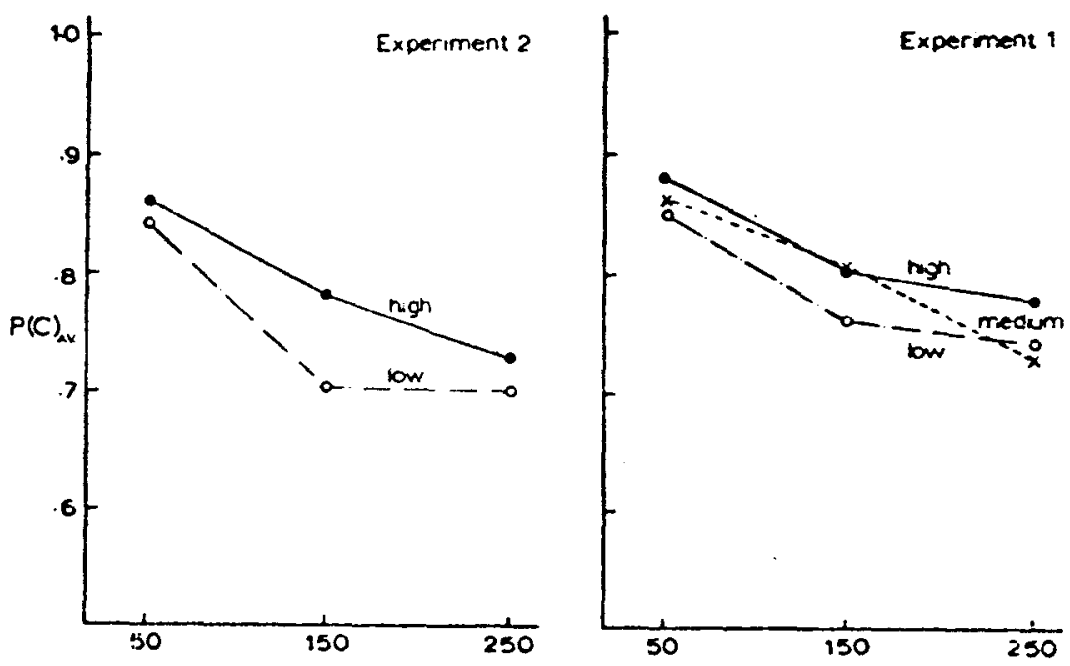

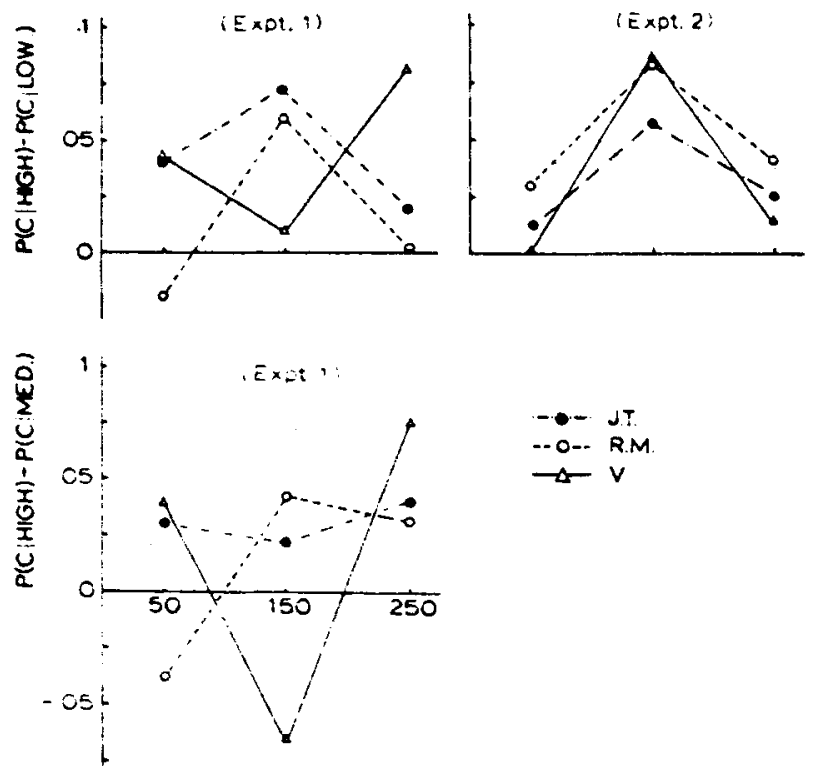

Fig. 2. The change in $\hat{P}(C)$ at each base duration when there is a change in the intensity of the signals bounding the intervals. Individual data.

base duration, $\dot{P}(C)$ with the high-intensity markers is greater than $\dot{P}(C)$ with the low-intensity markers. However, this difference is not a decreasing function of base duration, since in both versions it is nearly the same at $\mathrm{T}=50$ as at $\mathrm{T}=250$ (approximately .02); in Experiment 2, it is twice as large at $T=150$ as at 50 or 250 . Note that with the low-intensity markers, there is no change in $\hat{P}(C)$ when the base duration increases from 150 to 250 . This result holds for each of the individual Os; see Table 1.

Figure 2 shows the difference between $\hat{P}(C)$ at the high intensity and $\hat{P}(C)$ at the low intensity $-[P(C \mid$ high $)$ $-\hat{P}(C \mid$ low $)]$-plotted as a function of base duration for each $\mathrm{O}$. A larger difference at $\mathrm{T}=150$ than at 50 or 250 is seen for all three Os in Experiment 1 and for two of the three Os in Experiment 2. On the other hand, we do not find a similar pattern in the plot of $[\hat{P}(C \mid$ high $)-$ $\hat{\mathrm{P}}(\mathrm{C} \mid$ medium $)]$ from Experiment 1 ; here there is no tendency in the individual data for the difference to be somewhat larger at $\mathrm{T}=150$ than at $\mathrm{T}=50$ or 250 .

\section{DISCUSSION}

Our results indicate that, although there is an improvement in performance as marker intensity is increased over a fairly wide range, the change in $\mathbf{P}(C)$ is small. A binomial test was used to determine whether the differences between the proportions $\hat{\mathbf{P}}(\mathrm{C} \mid$ high $)$ and $\hat{\mathbf{P}}(\mathrm{C} \mid$ low $)$ at each base duration were large enough to be significant for individual Os. At both $T=50$ and $T=250$, these differences failed to reach significance at the .05 level in five instances out of six $(2$ versions $\times 3$ Os). At $T=150$, three of the six differences are significant. When $k$ independent tests are carried out on the same set of data with the significance level for each test set at $\alpha=.05$, the probability that one or more of these yield a spuriously significant result is $1-(1-\alpha)^{\mathbf{k}}$ $\cong \alpha \cdot \mathrm{k}$, for small $\alpha$ (Hays, 1963). Hence, some of the five differences, which were significant according to the test used, may be significant by chance alone.

The effect obtained here of increasing the intensity is small compared to the effects obtained by Creelman ${ }^{2}$ in his third experiment, where an increase in intensity of about $12 \mathrm{~dB}$ (corresponding to an increase in signal amplitude from .010 to $.042 \mathrm{rms} \mathrm{V}^{3}$ resulted in an increase in $\hat{\mathbf{P}}(\mathrm{C})$ of approximately .15 , with base durations ranging from 80 to $320 \mathrm{msec}$. However, the lower signal intensity $(.010 \mathrm{~V})$ was at the same voltage level as the background noise added at the earphones. Hence, as Creelman suggests, there may well have been considerable difficulty in detecting the onsets and offsets of the signals in the noise; there may have been difficulty in detecting even the presence of the shortest $(40 \mathrm{msec})$ signals on some trials. In his first experiment, a signal-to-noise ratio of about $10 \mathrm{~dB}$ was needed for asymptotic performance in discriminating between durations of 100 and $130 \mathrm{msec}$. Any large improvement in performance could reasonably be attributed to an increase in the number of trials on which the signals were detectable.

In this study, the low intensity was chosen so as to have signals which would be detected by the $O$ on each presentation; it was intended to avoid problems with detectability of the boundaries of the intervals. ${ }^{4}$ Nevertheless, the possibility cannot be discounted that on some trials the $\mathrm{O}$ might have missed one or more of the boundaries of the two intervals when the boundaries were faint.

An alternative interpretation of the small effect of intensity is that increasing the intensity of the brief signals bounding the external intervals decreases the variability in the latencies of the events bounding the internal intervals, resulting in a small increase in the detectability of a difference in duration between the two intervals. This interpretation seems plausible when we take into account the finding that both the mean and the variance of simple reaction times to auditory stimuli is decreased as stimulus intensity is increased (Green \& Luce, 1971; Murray, 1970).

Evidence from this experiment makes it seem quite unlikely that the discrimination between two brief empty auditory intervals in the range of $50-300 \mathrm{msec}$ is based on a code which uses the energy in the stimulus pattern defining these time intervals. If an interaction between the sensory effects of the two auditory pulses bounding an interval were being used as the basis for coding the time interval, it should be much less effective as a cue for duration discrimination when $T=250$ than when $\mathrm{T}=50$ or 150 . But we found that with the low-intensity boundaries there was no change in $\hat{P}(C)$ as the base duration increased from 150 to 250 . Moreover, decreasing the intensity of the pulses should 
systematically diminish the discriminability of a difference in the temporal distance between the pulses, but we found no such systematic change at $T=250$; $\hat{\mathrm{P}}(\mathrm{C})$ with the medium-intensity pulses was slightly less than with the low-intensity pulses. Finally, there is no indication that when the base duration is $50 \mathrm{msec}$, the code is intensity-dependent; the effect on $\hat{\mathbf{P}}(\mathrm{C})$ of changing the intensity of the boundaries was the same when $T=50$ as when $T=250$. Hence, these results reinforce the view that duration discrimination is based on an internal time code which is independent of energy effects, except perhaps secondarily, in that the variability of the latencies of the events bounding the internal intervals can be influenced by the intensity of the signals defining the external time intervals.

\section{REFERENCES}

Abel, S. M. Mechanisms for temporal numerosity in audition. Doctoral thesis, McMaster University, 1970.

Abel, S. M. The discrimination of temporal gaps. Journal of the Acoustical Society of America, 1972a, 52, 519-524.

Abel, S. M. Duration discrimination of noise and tone bursts. Journal of the Acoustical Society of America, 1972b, 51, 1219-1223.

Allan, L. G., Kristofferson, A. B., \& Wiens, E. W. Duration discrimination of brief light flashes. Perception \& Psychophysics, 1971, 9, 327-334.

Carbotte, R. M., \& Kristofferson, A. B. Discrimination of brief empty time intervals. Technical Report No. 21, Department of Psychology, McMaster University, March 1971.

Creelman, C. D. Human discrimination of auditory duration. Journal of the Acoustical Society of America, 1962, 34, 582-593.

Green, D. M., \& Luce, R. D. Detection of auditory signals presented at random times: III. Perception \& Psychophysics, $1971,9,257-268$.

Hays, W. L. Statistics for psychologists. New York: Rinehart \& Winston, 1963.

Kristofferson, A. B, \& Allan, L. G. Successiveness and duration discrimination. In S. Kornblum (Ed.), Attention and performance IV. New York: A cademic Press, 1973.

Massaro, D. W. Effect of masking tone on preperceptual auditory images. Journal of Experimental Psychology, 1971, 87, 146-148.

Murray, H. G. Stimulus intensity and reaction time: Evaluation of a decision theory model. Journal of Experimental Psychology, 1970, 84, 383-391.

Nilsson, T. H. Two-pulse interval thresholds of vision. Journal of the Optical Society of America, 1969, 59, 753-756.

Plomp, R. The rate of decay of auditory sensation. Journal of the Acoustical Society of America, 1964, 36, 277-282.

Stevens, J. C., \& Hall, J. W. Brightness and loudness as functions of stimulus duration. Perception \& Psychophysics, 1966, 1, 319-327.

Swets, J. A. (Ed.) Signal detection and recognition by human observers. Contemporary readings. New York: Wiley, 1964.

Woodrow, H. Time perception. In S. S. Stevens (Ed.), Handbook of experimental psychology. New York: Wiley, 1951. Chap. 32.

\section{NOTES}

1. This averaging is intended only to show the main features of the individual data; any conclusions drawn from this figure will have to hold for each individual 0 .

2. It would be of considerable interest to compare our results with those obtained by Abel (1972b) with empty intervals, but this is not possible, since her dependent variable was $\Delta \mathrm{T} .75$. There is no way of using the change in $\Delta T$ required for a fixed performance level, to predict the change in $\hat{\mathbf{P}}(\mathrm{C})$ with a fixed value of $\Delta T$, unless we have the complete psychometric functions relating $\hat{P}(C)$ to $\Delta T$ at the two intensity levels.

3. An increase in signal voltage from $v_{1}$ to $v_{2}$ corresponds to an increase in sound pressure level of $20 \log _{10}\left(v_{2} / v_{1}\right)$.

4. The intensity at which a $10-\mathrm{msec}$ pulse was less than fully detectable was less than $.03 \mathrm{rms} V$. This was determined informally, with the $E$ acting as an $O$ for blocks of 70 trials. With a yes-no detection procedure (i.e., with the signal absent on half the trials), the signal was fully detectable at each of several intensities between .03 and $.08 \mathrm{~V}$.

(Received for publication January 15, 1973; revision received July 5,1973 .) 